\title{
Evaluating Interfacial Stability in Solid-State Pouch Cells Via
}

\section{Ultrasonic Imaging}

Hanyu Huo ${ }^{1,6 \dagger}$, Kai Huang ${ }^{2,3, \dagger}$, Wei Luo ${ }^{1 *}$, Jintao Meng ${ }^{2}$, Liangyi Zhou ${ }^{2}$, Zhe Deng ${ }^{2,3}$, Jiayun Wen ${ }^{1}$, Yiming Dai ${ }^{1}$, Zhimei Huang ${ }^{2}$, Yue Shen ${ }^{2,3 *}$, Xiangxin Guo $^{4}$, Xiulei Ji ${ }^{5}$, Yunhui Huang ${ }^{2 *}$

${ }^{1}$ Institute of New Energy for Vehicles, School of Materials Science and Engineering, Tongji University, Shanghai 201804, China

${ }^{2}$ State Key Laboratory of Material Processing and Die \& Mould Technology, School of Materials Science and Engineering, Huazhong University of Science and Technology, Wuhan, Hubei 430074, China

${ }^{3}$ HUST- Wuxi Research Institute, Wuxi, Jiangsu 214000, China

${ }^{4}$ College of Physics, Qingdao University, Qingdao 266071, China

${ }^{5}$ Department of Chemistry, Oregon State University, Corvallis, OR, 97331-4003, USA

${ }^{6}$ Present address: Institute of Physical Chemistry, Justus Liebig University of Giessen, 35392 Giessen, Germany

†These authors contributed equally to this work

* Corresponding authors.

Email address: weiluo@tongji.edu.cn; shenyue1213@hust.edu.cn; and huangyh@hust.edu.cn 


\section{Experimental Procedures}

\section{Fabrication of the PLLZ@BC}

PEO $\left(\mathrm{Mv}=6 \times 10^{5} \mathrm{~g} \mathrm{~mol}^{-1}\right.$, Aladdin) was dried at $60{ }^{\circ} \mathrm{C}$ overnight under vacuum prior to the electrolyte fabrication. $\mathrm{Li}_{6.4} \mathrm{La}_{3} \mathrm{Zr}_{1.4} \mathrm{Ta}_{0.6} \mathrm{O}_{12}$ (LLZTO) ceramic powders were prepared by the solid-state reaction and crushed by planetary high-energy ball-milling to decrease the particle size from $5 \mu \mathrm{m}$ to $200 \mathrm{~nm}{ }^{1}$. $20 \mathrm{wt} \%$ LLZTO particles were added into ACN (15 mL) and dispersed by sonication to improve the dispersion. After that, PEO and LiTFSI $\left(\mathrm{EO} / \mathrm{Li}^{+}=12: 1\right.$ by mol $)$ were added into the solution and stirred continuously for $8 \mathrm{~h}$. Then, the homogenized colloidal solution was cast onto a glass plate with a controlled thickness. The ACN solvent was evaporated in a vacuum oven at $80{ }^{\circ} \mathrm{C}$ for $24 \mathrm{~h}$. The thickness of the PLLZ@BC was approximately $100 \mu \mathrm{m}$.

\section{Fabrication of the PLLZ@HP}

LLZTO powders, PEO, and LiTFSI were homogenously mixed and ground in a mortar to obtain a small ball. The EO to Li molar ratio was 12:1 and the content of LLZTO powders was $20 \mathrm{wt} \%$. Subsequently, the small ball was sandwiched between two pieces of polytetrafluoroethylene (PTFE) plates and transferred into a vacuum oven. By pressing for $2 \mathrm{~h}$ at $100{ }^{\circ} \mathrm{C}$ under $20 \mathrm{MPa}$, a uniform composite electrolyte membrane with the thickness of approximately $100 \mu \mathrm{m}$ was successfully fabricated.

\section{Characterizations of material properties}

Surface and cross-section morphologies of composite electrolytes were investigated by scanning electron microscopy (SEM, S3400). Thermogravimetric analysis (TGA) was tested from 30 to $500{ }^{\circ} \mathrm{C}$ at $10{ }^{\circ} \mathrm{C} \mathrm{min}{ }^{-1}$ under Ar atmosphere. Fourier transform infrared (FTIR) spectroscopy was conducted using a Bruker Alpha system with a Diamond attenuated total reflection (ATR) window in the range of 4000 to $400 \mathrm{~cm}^{-1}$ at a resolution of $4 \mathrm{~cm}^{-1}$. X-ray photoelectron spectroscopy (XPS, ESCALAB-250) measurements was performed to characterize composition of composite electrolytes before and after cycling. All air-sensitive samples were transferred by Leica transfer module.

\section{Electrochemical Performance Tests}

The ionic conductivities of the composite electrolytes were measured by the NOVOCONTROL spectrometer fitted with a temperature control system with the frequency range from $0.01 \mathrm{~Hz}$ to $40 \mathrm{MHz}$. The electrolytes were sandwiched between two stainless steels (SS), which were used as the block electrodes. The ionic conductivity $\sigma$ was calculated based on the following equation:

$$
6=\frac{\mathrm{t}}{\mathrm{RA}}
$$

Where $\mathrm{t}$ represents the thickness of the electrolyte membrane, $\mathrm{R}$ is the bulk resistance of electrolytes, and A refers to the contact area between electrolytes and electrodes. Electrochemical impedance spectroscopy (EIS) measurements were performed in a 
frequency range from $1 \mathrm{MHz}$ to $0.1 \mathrm{~Hz}$ with an amplitude of $10 \mathrm{mV}$ by an Autolab instrument. Galvanostatic cycling tests were conducted using a NEWARE battery cycler (CT-4000) using different current densities at $45{ }^{\circ} \mathrm{C}$. The electrochemical window was examined by SS/electrolyte/Li cells, using linear sweep voltammetry (LSV), which was conducted from $2 \mathrm{~V}$ to $5.5 \mathrm{~V}$ at a scan rate of $0.1 \mathrm{mV} \mathrm{s}^{-1}$ by Arbin BT-2000.

Differential electrochemical mass spectrometry (DEMS) was used to test the gas produced by the chemical decomposition of the composite electrolytes, the gas produced of $\mathrm{Li} / \mathrm{Li}$ symmetric cells and $\mathrm{LiCoO}_{2} / \mathrm{Li}$ cells using a customized Swagelok battery mold for testing. Mass signals $m / z, 2,4,16,28,30$ correspond to $\mathrm{H}_{2}, \mathrm{He}, \mathrm{CH}_{4}$, $\mathrm{C}_{2} \mathrm{H}_{4}, \mathrm{C}_{2} \mathrm{H}_{6}$.

The composite cathode was prepared as follows: $\mathrm{LiCoO}_{2}$ was mixed with PEO, PVDF, super $\mathrm{P}$ conductive carbon (SP) and LiTFSI in 1-methyl-2-pyrrolidinone (NMP, anhydrous, $99.5 \%$ ) under vigorous agitation. The homogenized suspension was then casted on a carbon-coated $\mathrm{Al}$ foil with a doctor blade, followed by drying at $55^{\circ} \mathrm{C}$ for $6 \mathrm{~h}$ in air and in vacuum condition at $100{ }^{\circ} \mathrm{C}$ for $6 \mathrm{~h}$. The mass ratio of $\mathrm{LiCoO}_{2}: \mathrm{SP}$ : PEO: PVDF was 75: 10: 10: 5 by weight and the amount of LiTFSI was based on the content of PEO $(\mathrm{EO} / \mathrm{Li}=12: 1)$. The LCO loading is approximately $2 \mathrm{mg} \mathrm{cm}^{-2}$, and the cathode area is $2.5 \mathrm{~cm} \times 3 \mathrm{~cm}$. No additional presure for all battery cycling.

\section{Ultrasonic imaging}

To capture the ultrasonic image, ultrasonic battery scanner (USBC-LD50, from Jiangsu Jitri-Hust Intelligent Equipment Technology Co., Ltd) was applied to accomplish the test. USBC-LD50 main consists of acoustic medium module, motion module and data acquisition module. Pouch cell was fixed in the low-viscosity silicone oil (PMX-200, $10 \mathrm{cSt}$, Dow Corning Co., Ltd) bath, which connect to the battery test equipment (CT4008T, Neware Technology Co., Ltd). Two focusing transducers (2 MHz frequency, $40 \mathrm{~mm}$ focal distance, focusing diameter $<1 \mathrm{~mm}$, customized from Shantou Institute of Ultrasonic Instruments Co., Ltd.) were put on both sides of cell to transmit and receive ultrasonic waves. The motion module could provide an exquisite scanning in horizontal and vertical directions. In this work, $0.2 \mathrm{~mm}$ precision was chosen to perform the experiment which takes about $300 \mathrm{~s}$ to finish scale scanning. For matching the $2 \mathrm{MHz}$ frequency transducers, a $200 \mathrm{~V}$ impulse with $250 \mathrm{~ns}$ width as the driving signal. Each transmitted signal during scanning could be gathered by data acquisition card and transform into a waveform with a peak-to-peak value (PPV) eigenvalue. Further, PPV was converted into a color scale to make the pseudo color image. To evaluate the sensitivity of the ultrasonic imaging, $3 \mu \mathrm{L}$ gas was generated in the pouch cell by the thermal decomposition of Azobisisobutyronitrile (AIBN) at $85^{\circ} \mathrm{C}$. Such small amount of gas can be well reflected in the ultrasonic image (Fig. S16). It is estimated that $6 \mu \mathrm{m}$ void/gap is detectable according to the gas area, thus showing a good sensitivity. 


\section{DFT calculations}

DFT calculations were carried out by the modules DMol3 ${ }^{2,3}$ and CASTEP ${ }^{4}$ in Materials Studio 2017. B3LYP functional in $\mathrm{Dmol}^{3}$ module was used to calculate the geometry optimization, energies of the highest and lowest occupied molecular orbitals (HOMO and LUMO). Geometry optimizations were obtained until the maximum force values are less than $0.002 \mathrm{Ha} / \mathrm{A}$ and the maximal atomic displacement is less than $5.0 \mathrm{e}-$ $3 \AA$. Core treatment is all-electron using a fine integration grid. Stable self-consistent field (SCF) solutions were obtained, and all structures were optimized. The basis set was DNP (double numerical plus polarization) and the basis file was 3.5.

In CASTEP module calculation, the reaction energies of reactions (2-4) were obtained from the subtraction of total energy of reactants from that of resultants. Total energies of each reactant and resultant were calculated through periodic boundary conditions (PBC) after each single molecule is put into a $20.0 \AA$ cubic unit cell. The generalized gradient approximation (GGA) within Perdew, Burke and Ernzerhof (PBE) is used for exchange-correlation energy. We choose ultrasoft pseudopotential as the core electrons treatment and Broyden-Fletcher-Goldfarb-Shanno (BFGS) scheme as the minimization algorithm respectively. And the valence electron functions were expanded into a set of numerical atomic orbitals using DNP. Geometry optimizations were employed until the maximal energy change per atom is less than $1.0 \mathrm{e}^{-5} \mathrm{eV}$. The maximal force on the atoms was less than $0.03 \mathrm{eV}^{-1}$. The maximal stress was less than 0.05 and the maximal atomic displacement was less than $1.0 \mathrm{e}^{-3} \AA$. The energy cutoff was set to as $500 \mathrm{eV}$ and Monkhorst-Pack k-point mesh was $1 \times 1 \times 1$.

$$
\begin{aligned}
& 2 \mathrm{Li}+2 \mathrm{CH}_{3} \mathrm{CN} \rightarrow 2 \mathrm{LiCN}+\mathrm{C}_{2} \mathrm{H}_{6} \\
& 2 \mathrm{Li}+2 \mathrm{CH}_{3} \mathrm{CN} \rightarrow 2 \mathrm{LiCN}+\mathrm{C}_{2} \mathrm{H}_{4} \\
& 2 \mathrm{Li}+4 \mathrm{CH}_{3} \mathrm{CN} \rightarrow 2 \mathrm{LiCN}+2 \mathrm{CH}_{4}+\mathrm{NC}\left(\mathrm{CH}_{2}\right)_{2} \mathrm{CN}
\end{aligned}
$$

The reaction energy $(\triangle \mathrm{E})$ was calculated using the equation:

$\triangle \mathrm{E}=E_{\text {resultants }}-E_{\text {reactants }}$

$\triangle \mathrm{E}<0$ indicates that the reaction is an exothermic process and thermodynamically feasible. 

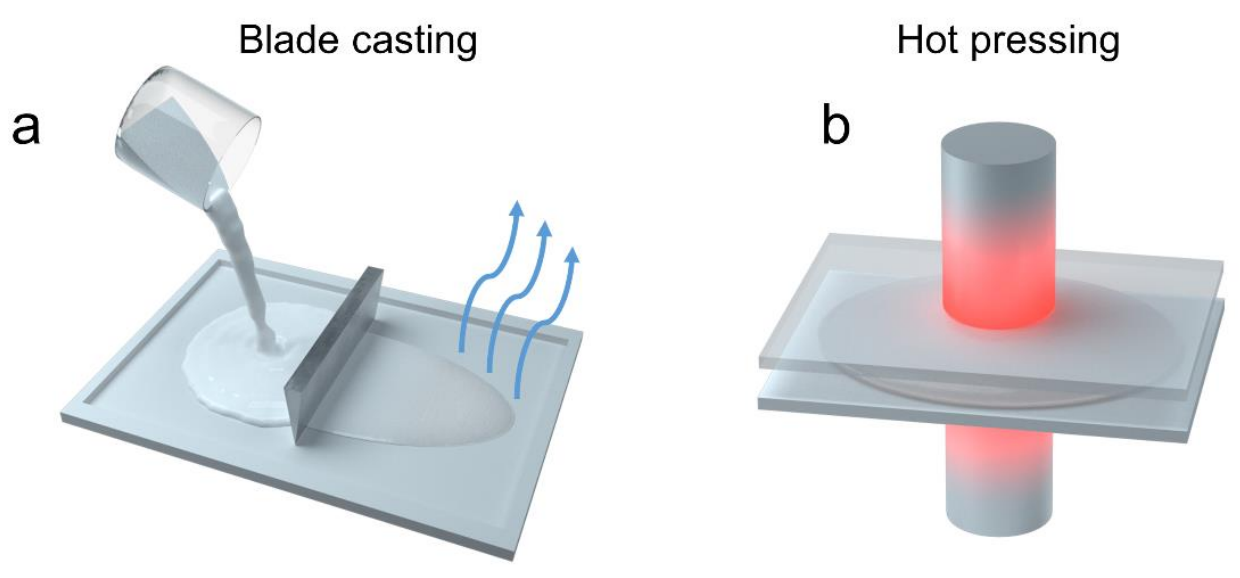

Fig. S1 Schematic images of the fabrication of electrolyte membranes by the (a) blade casting and (b) hot pressing. 

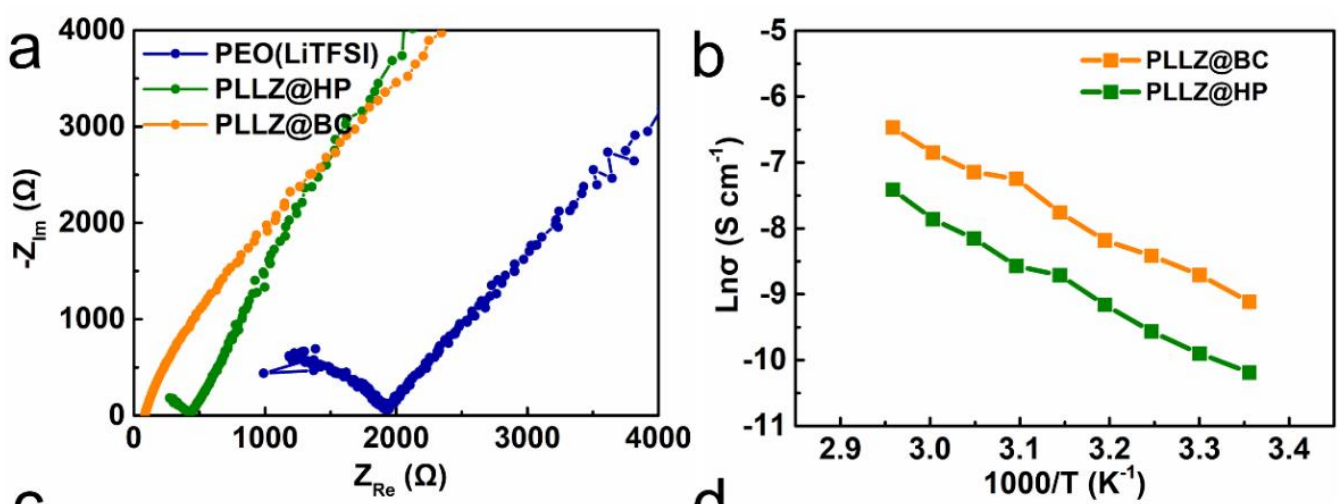

C
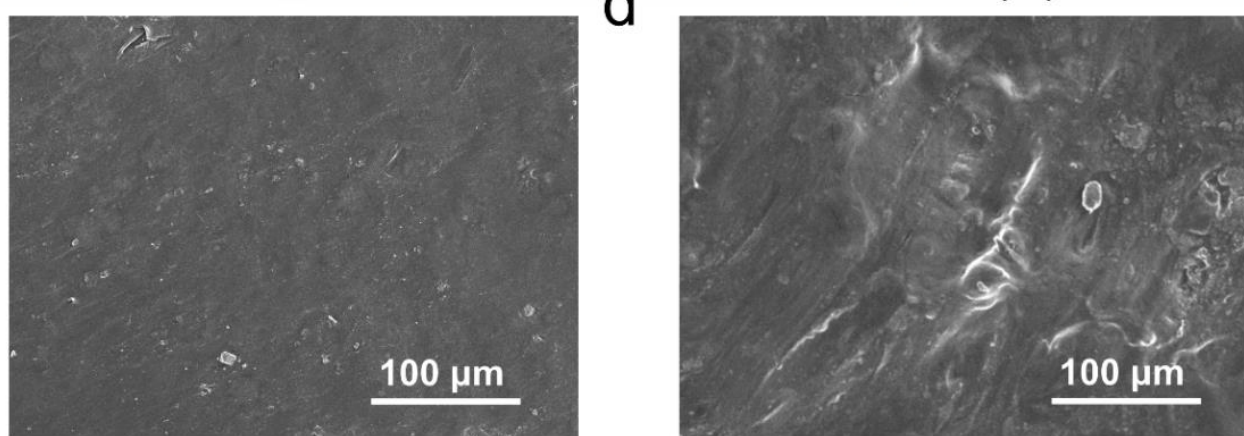

Fig. S2 (a) EIS spectra of the PEO(LiTFSI), PLLZ@HP, and PLLZ@BC at $25^{\circ} \mathrm{C}$. (b) Arrhenius plots of the PLLZ@HP and PLLZ@BC. Top-view SEM images of the (c) PLLZ@BC, and (d) PLLZ@HP. 


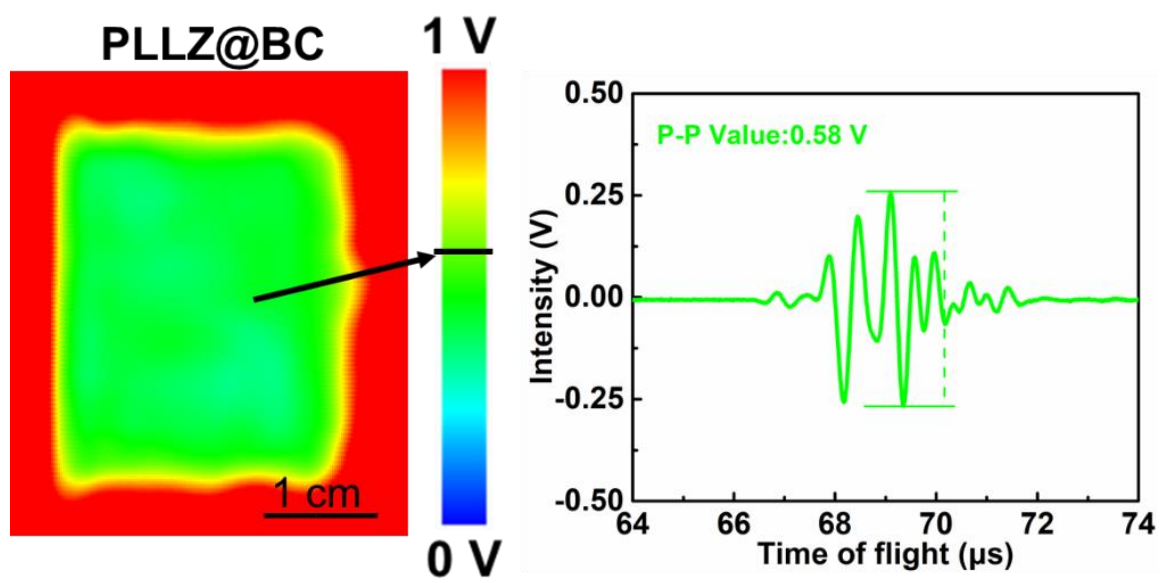

Fig. S3 The ultrasonic transmission image of the PLLZ@BC and the ultrasonic wave at the position marked by the arrow. 

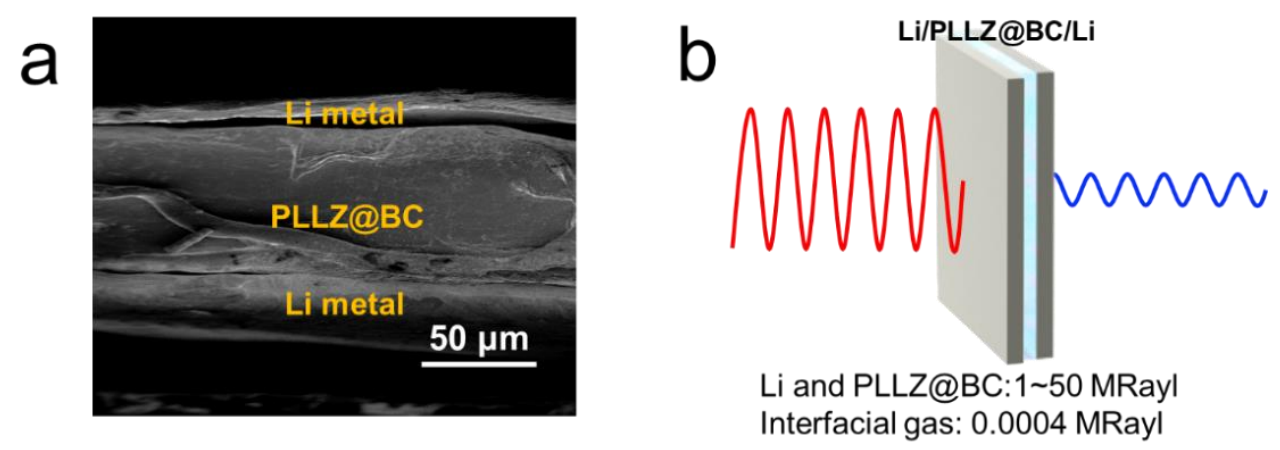

Fig. S4 (a) Cross-sectional SEM image of the Li/PLLZ@BC/Li cell. (b) Schematic image of ultrasonic signal passing through the Li/PLLZ@BC/Li cell. 

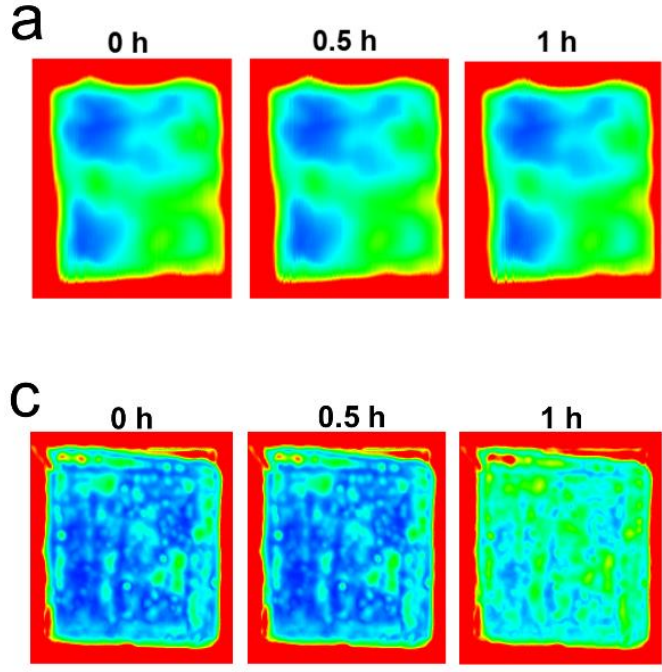

Unwetting

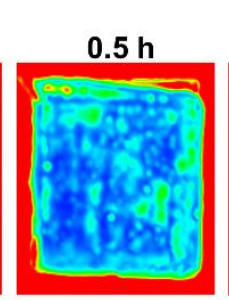

Hot-pressing at $60^{\circ} \mathrm{C}$
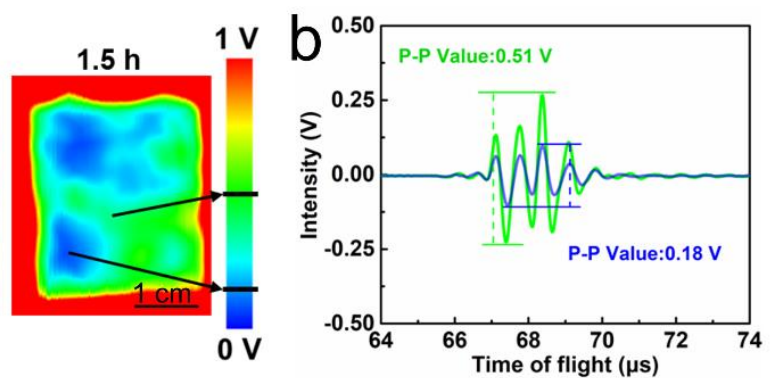

$1 \mathrm{v}$

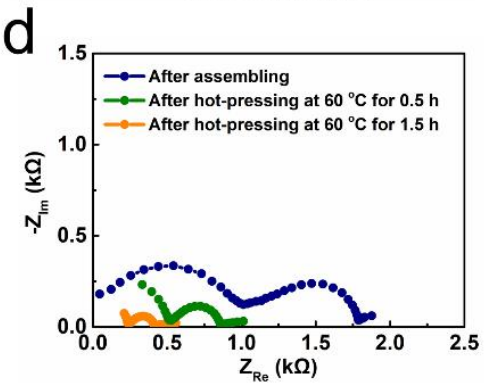

Fig. S5 (a) The ultrasonic transmission images of the Li/PLLZ@HP/Li cell after different time. (b) The ultrasonic waves at the positions marked by the arrows. (c) The interfacial wetting process of the Li/PLLZ@HP/Li cell during the hot-pressing at $60^{\circ} \mathrm{C}$. (d) EIS spectra of the Li/PLLZ@HP/Li cell after assembling, and after hot-pressing at $60{ }^{\circ} \mathrm{C}$ for 0.5 and $1.5 \mathrm{~h}$. 


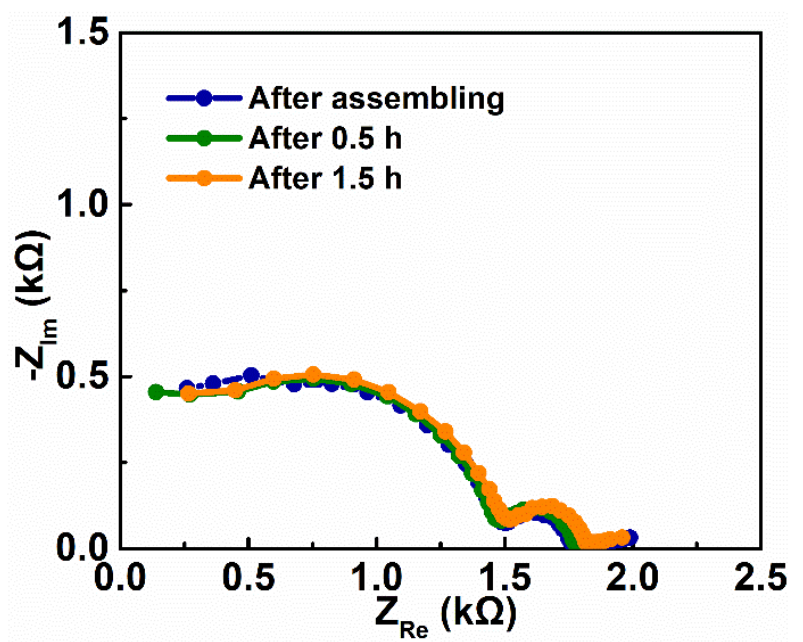

Fig. S6 EIS spectra of the Li/PLLZ@HP/Li cell after different time. 


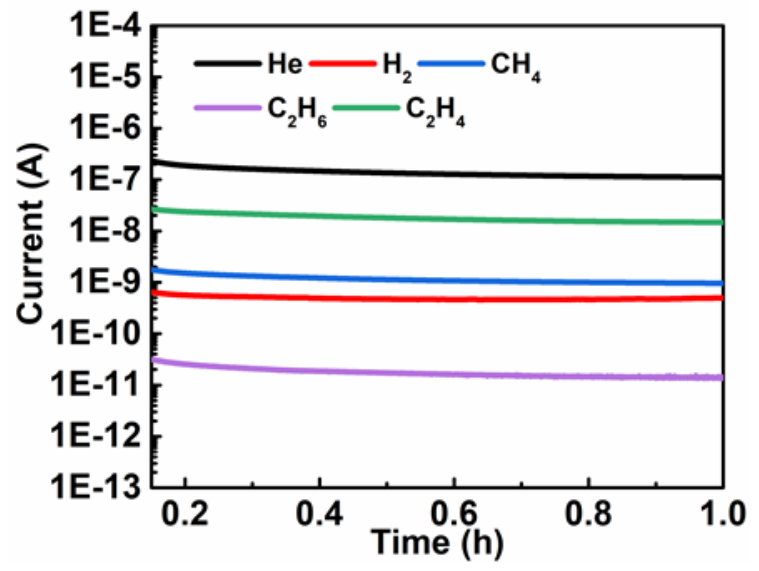

Fig. S7 DEMS results for the Li/PLLZ@HP/Li cell without charge/discharge process. 


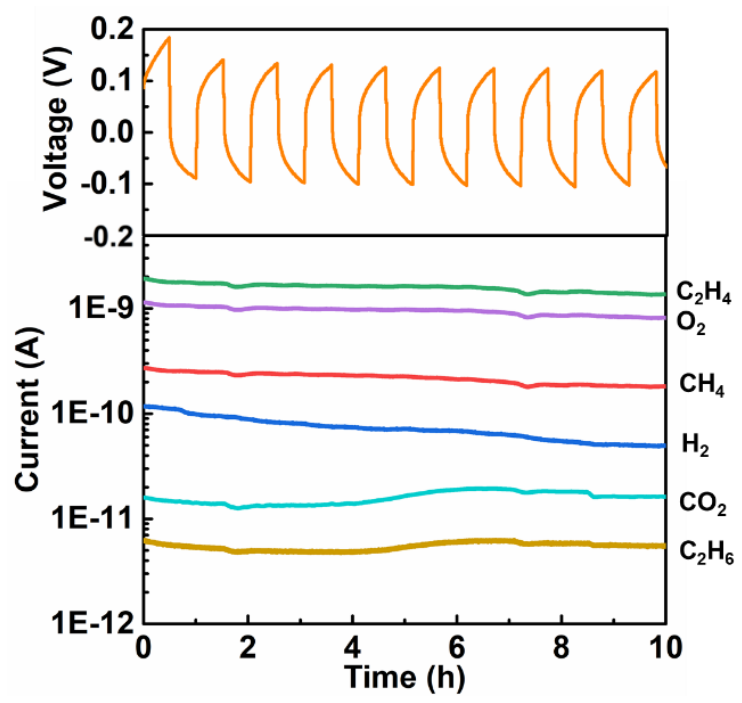

Fig. S8 Voltage profile and corresponding DEMS results of the Li/PLLZ@HP/Li cell cycled at $0.1 \mathrm{~mA} \mathrm{~cm}^{-2}$ and $45^{\circ} \mathrm{C}$. 

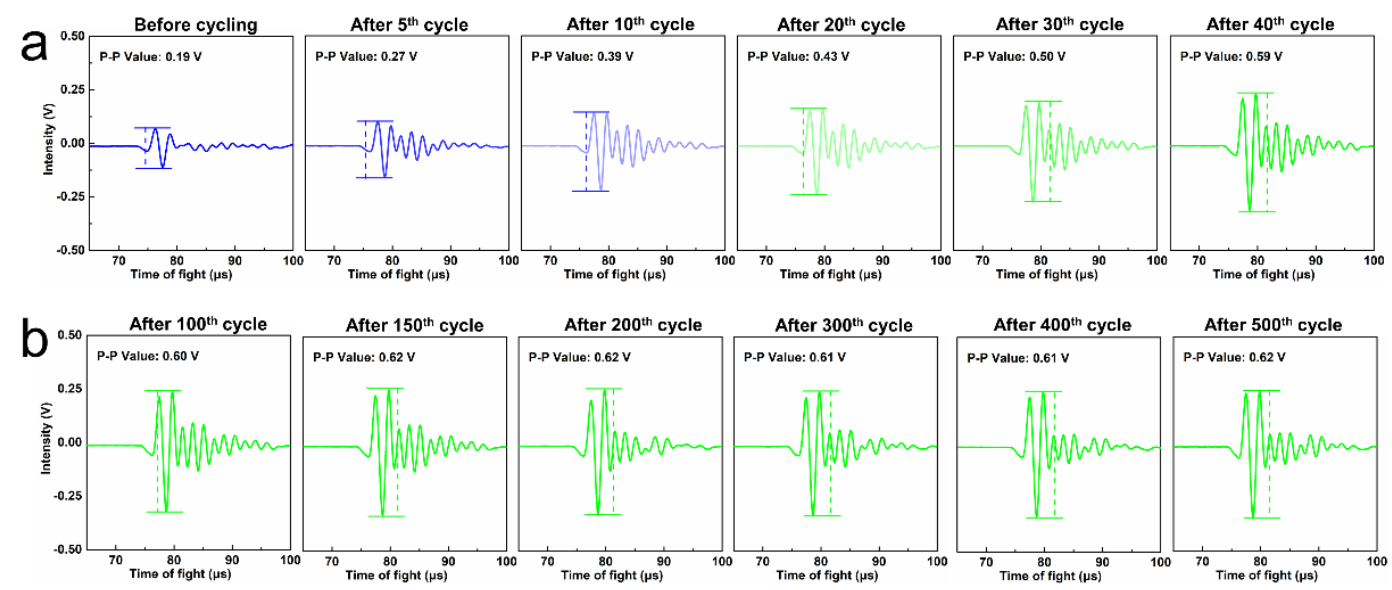

Fig. S9 Ultrasonic waves of the Li/PLLZ@HP/Li cell at a fixed-point during (a) the interfacial activation process, and (b) the passivation layer growth. 


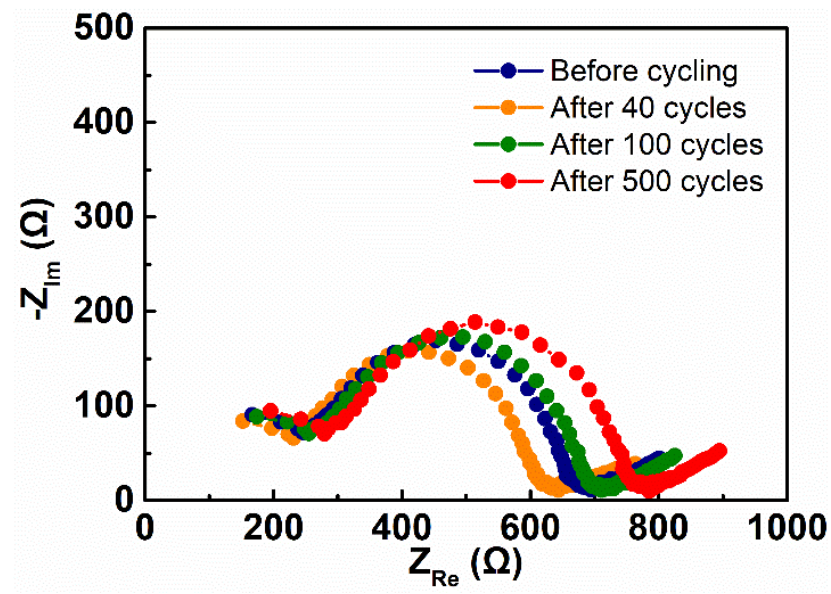

Fig. S10 EIS spectra of the Li/PLLZ@HP/Li cell after various cycles at $0.1 \mathrm{~mA} \mathrm{~cm}{ }^{-2}$. 

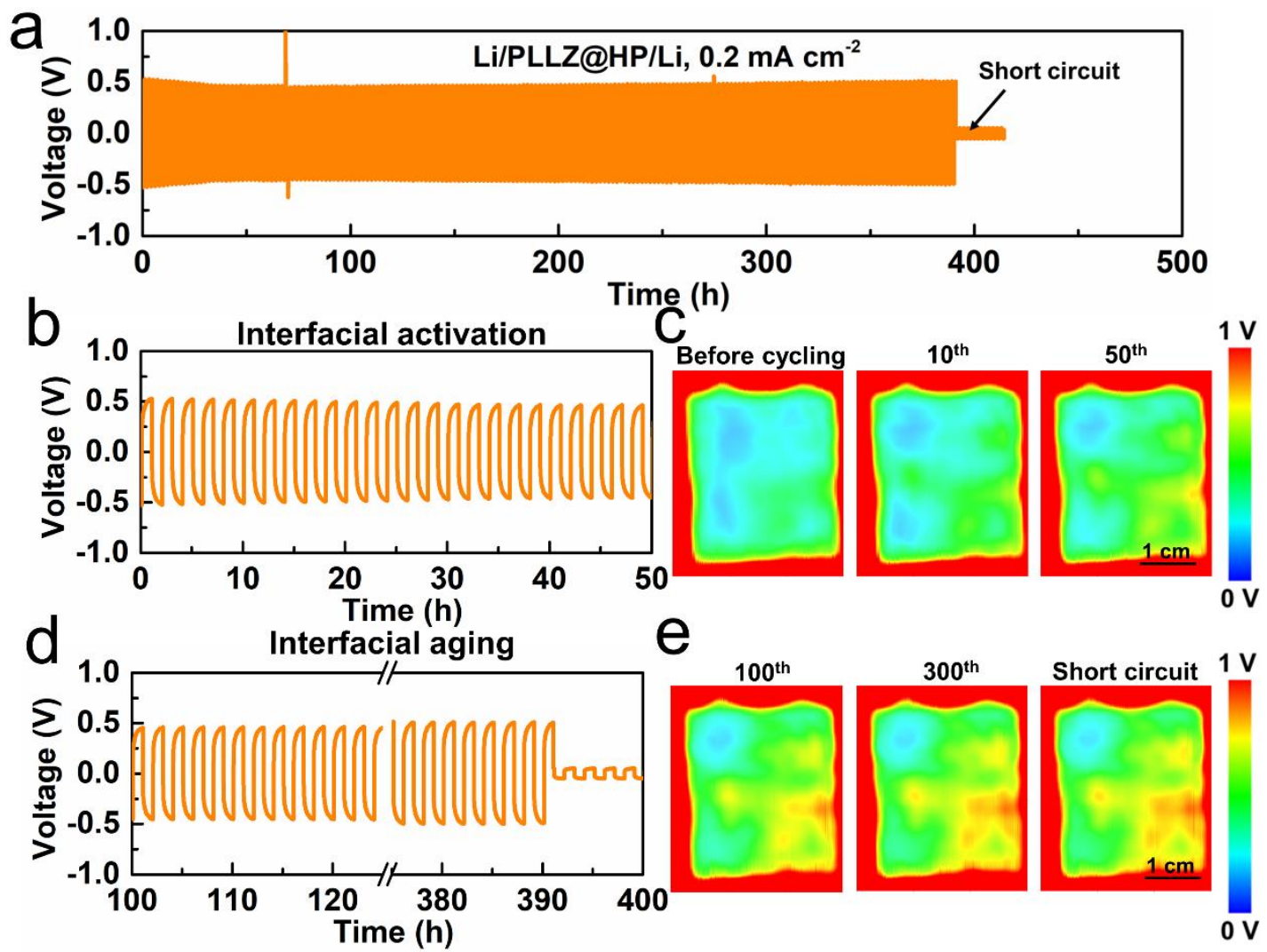

Fig. S11 (a) Galvanostatic cycling performance of the Li/PLLZ@HP/Li cell at $0.2 \mathrm{~mA}$ $\mathrm{cm}^{-2}\left(0.1 \mathrm{mAh} \mathrm{cm}^{-2}\right)$ at $45^{\circ} \mathrm{C}$. (b) Magnified image for 0-50 h. (c) The corresponding ultrasonic transmission images of the Li/PLLZ@HP/Li cell during the initial cycling. (d) Magnified image for 100-400 h. (e) The corresponding ultrasonic transmission images of the Li/PLLZ@HP/Li cell during the following cycling. 

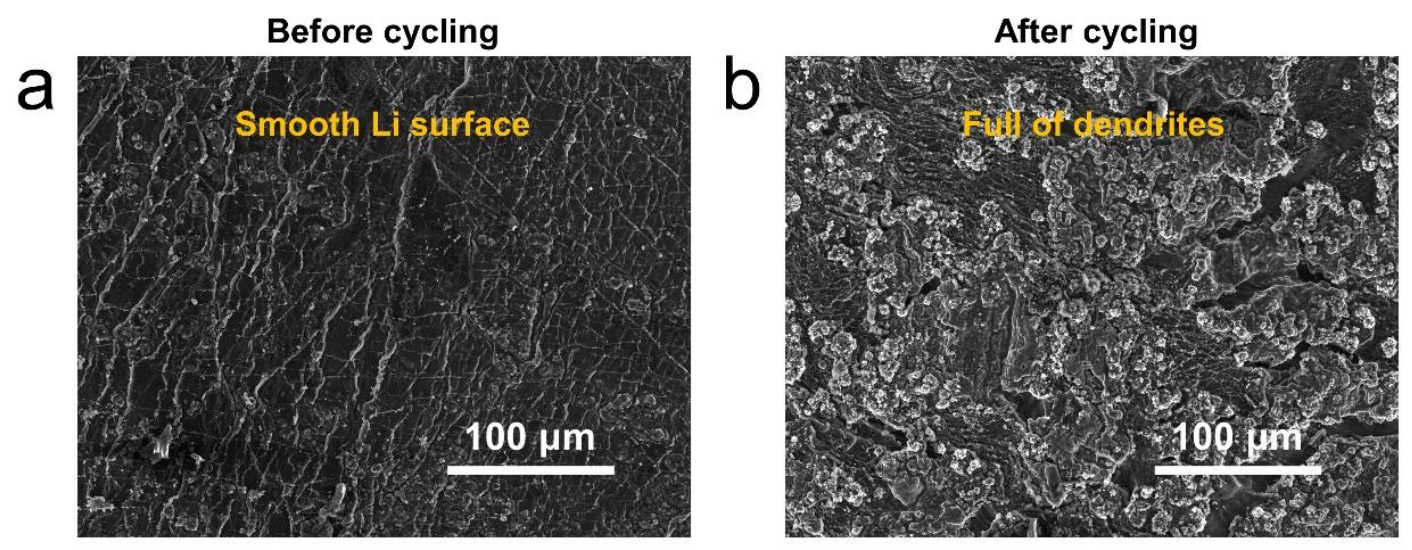

Fig. S12 Top-view SEM images of Li metal in Li/PLLZ@HP/Li cell (A) before and (B) after cycling. 


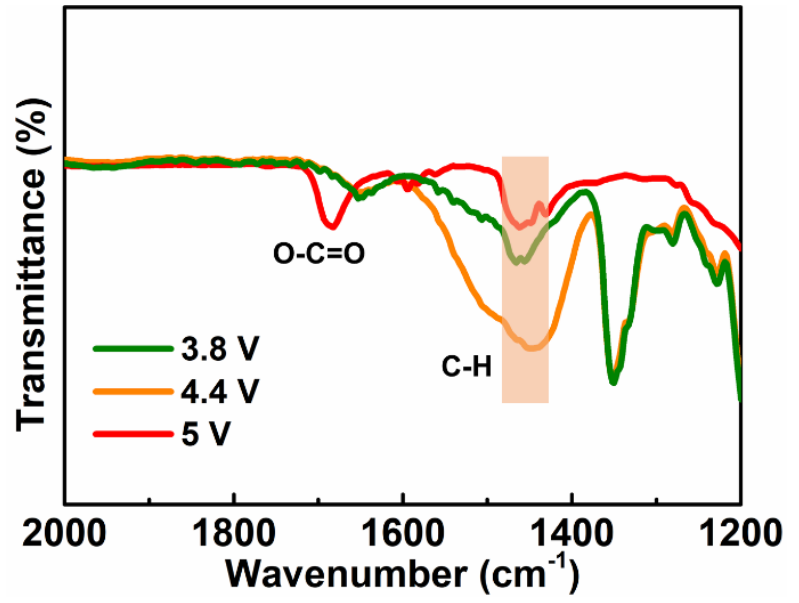

Fig. S13 FTIR spectra of the PLLZ@HP at different voltages. 

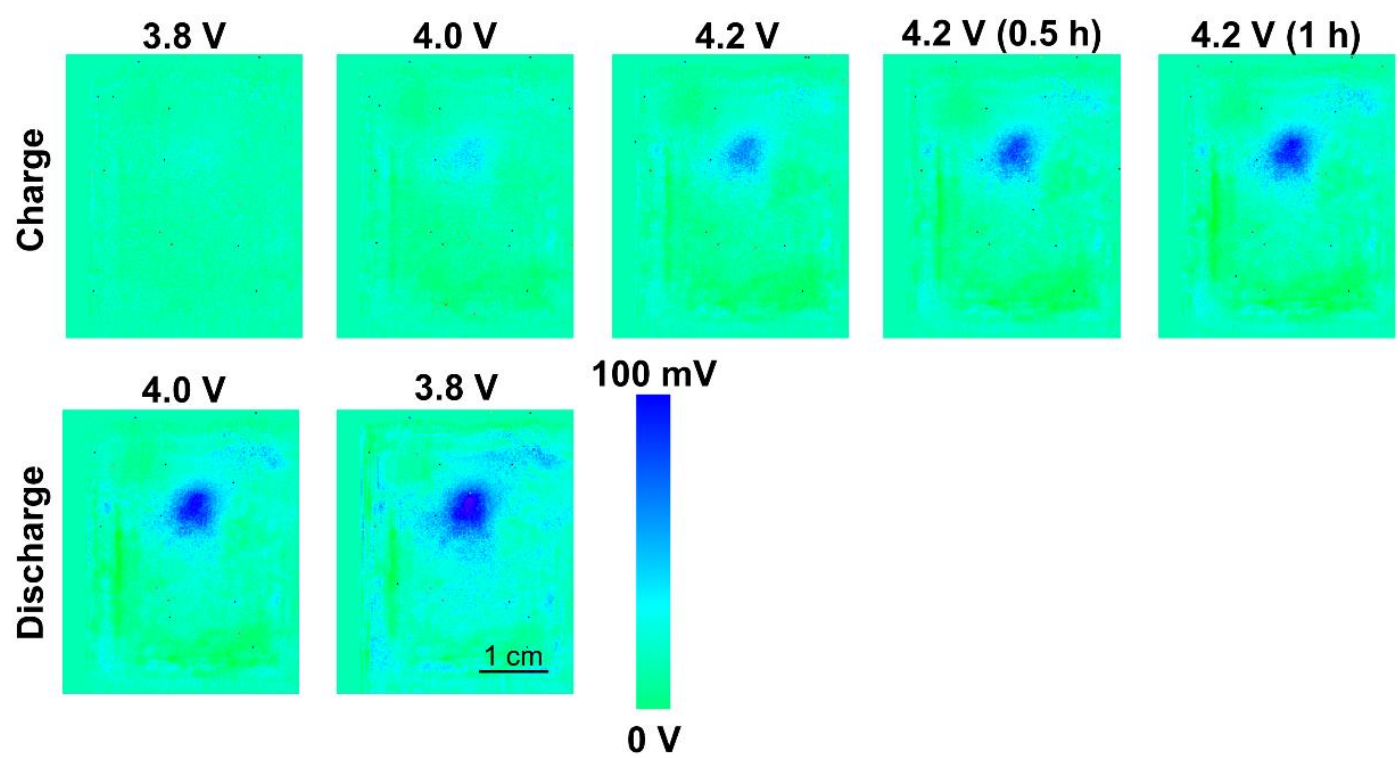

Fig. S14 Differential ultrasonic images of the LCO/PLLZ@HP/Li cell during the cycling at $0.1 \mathrm{C}$. 

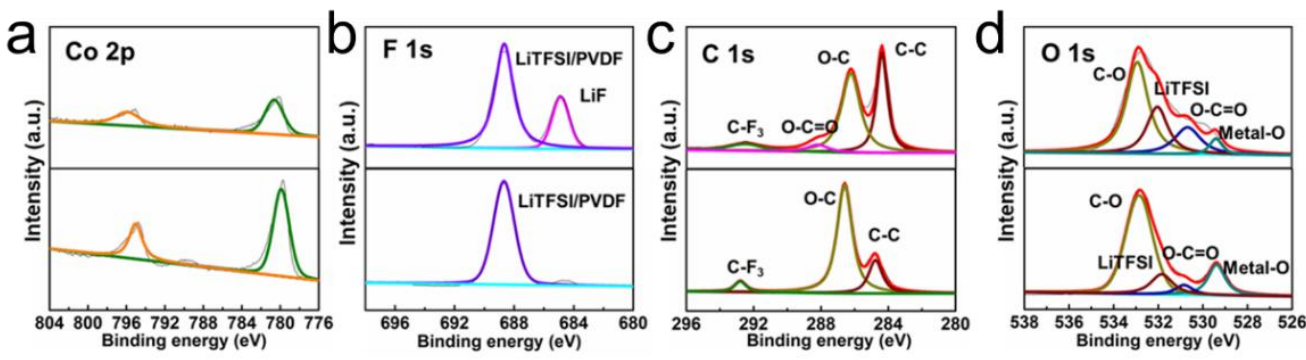

Fig. S15 (A) Co 2p, (B) F 1 s, (C) C 1s, and (D) O 1s XPS spectra of LCO cathode before and after cycling.

XPS was carried out to compare the LCO cathode before and after cycling. Co $2 p$ spectra show no change of Co chemical valence during cycling up to $4.2 \mathrm{~V}$. The peak at $688.6 \mathrm{eV}$ in the $\mathrm{F} 1 \mathrm{~s}$ spectrum corresponds to the Poly(vinylidene fluoride) (PVDF) binder and LiTFSI ${ }^{5}$. A new peak of LiF at $684.8 \mathrm{eV}$ is obtained after cycling, which could be attributed to the oxidation of LiTFSI at a high voltage. LiF with an ultralow ionic conductivity can hinder the $\mathrm{Li}^{+}$transport in the $\mathrm{LCO}$ cathode, thus leading to the fast capacity decay. Three peaks at $284.3,286.2$, and $292.4 \mathrm{eV}$ are obtained in the $\mathrm{C} 1 \mathrm{~s}$ spectrum, which can be assigned to $\mathrm{C}-\mathrm{C}, \mathrm{C}-\mathrm{O}$, and $\mathrm{CF}_{3}$ in the pristine $\mathrm{LCO}$ cathode, respectively ${ }^{6}$. The intensity of $\mathrm{C}-\mathrm{C}$ peak decreases and a new peak of $\mathrm{O}-\mathrm{C}=\mathrm{O}$ at 288.1 $\mathrm{eV}$ occurs after cycling. The oxidation of PEO molecular skeleton is also confirmed by the $\mathrm{O} 1 \mathrm{~s}$ spectrum. 


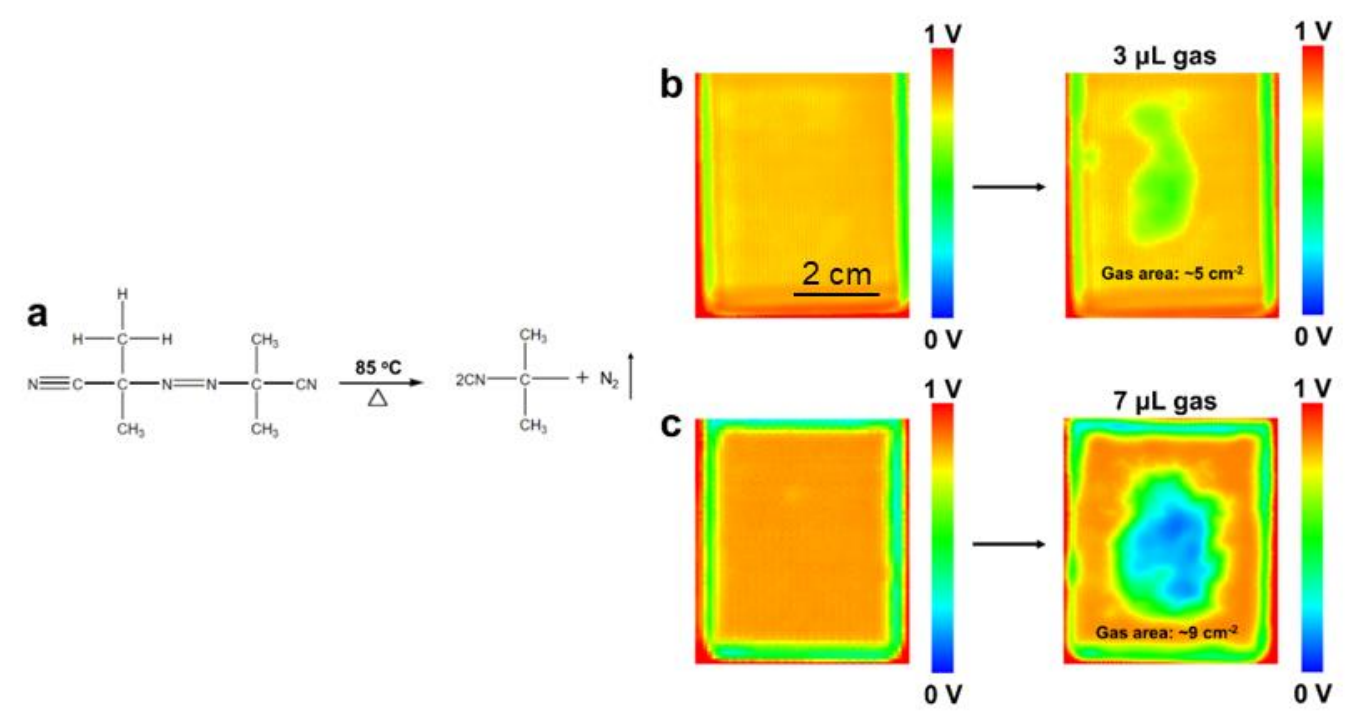

Fig. S16 (a) Thermolysis equation of Azobisisobutyronitrile (AIBN) at $85{ }^{\circ} \mathrm{C}$. Ultrasonic images before and after (b) $3 \mu \mathrm{L}$, and (c) $7 \mu \mathrm{L} \mathrm{N} \mathrm{N}_{2}$ generation in the pouch cells.

$36.65 \mathrm{mg}$ AIBN was added into $5 \mathrm{~mL}$ methylpyrrolidone (NMP)/ethanol (1:1) solvent and stirred for $6 \mathrm{~h}$, forming $0.0446 \mathrm{~mol} \mathrm{~L}^{-1}$ AIBN solution. Then, AIBN solution $(3 \mu \mathrm{L}$ and $7 \mu \mathrm{L}$ ) was dipped into the separator and vacuum dried at $50{ }^{\circ} \mathrm{C}$ for $1 \mathrm{~h}$ to remove the solvent. Pouch cells $(4.5 \mathrm{~cm} \times 5 \mathrm{~cm})$ were assembled with $2.8 \mathrm{~mL}$ liquid electrolyte and rested for $6 \mathrm{~h}$. Ultrasonic imaging was carried out when the electrolyte was fully wetted the separator. Then, heating the pouch cells at $85{ }^{\circ} \mathrm{C}$ for $2 \mathrm{~h}$, which leads to the decomposition of AIBN and releases $\mathrm{N}_{2}$ in the pouch cells (Fig. S16a). The ultrasonic images were subsequently obtained for comparison at $25^{\circ} \mathrm{C}$.

As shown in Fig. S16b, $3 \mu \mathrm{L} \mathrm{N} \mathrm{N}_{2}$ can be well reflected in the pouch cell as the green region. It is estimated that $6 \mu \mathrm{m}$ void/gap is detectable by our ultrasonic equipment according to the gas area of $5 \mathrm{~cm}^{-2}$. When the gas amount increases to $7 \mu \mathrm{L}$, the ultrasonic signal further attenuates, leading to the blue color in the gas region (Fig. S16c). 


\section{References}

(1) Li, Y.; Cao, Y.; Guo, X. Influence of lithium oxide additives on densification and ionic conductivity of garnet-type $\mathrm{Li}_{6.75} \mathrm{La}_{3} \mathrm{Zr}_{1.75} \mathrm{Ta}_{0.25} \mathrm{O}_{12}$ solid electrolytes. Solid State Ionics 2013, 253, 76-80.

(2) Delley, B. An all-electron numerical method for solving the local density functional for polyatomic molecules. J. chemical phys. 1990, 92 (1), 508-517.

(3) Delley, B. From molecules to solids with the DMol 3 approach. J. Chem. Phys. 2000, 113 (18), 7756-7764.

(4) Clark, S. J.; Segall, M. D.; Pickard, C. J.; Hasnip, P. J.; Probert, M. I.; Refson, K.; Payne, M. C. First principles methods using CASTEP. Zeitschrift für KristallographieCrystalline Materials 2005, 220 (5-6), 567-570.

(5) Qiu, J.; Liu, X.; Chen, R.; Li, Q.; Wang, Y.; Chen, P.; Gan, L.; Lee, S. J.; Nordlund, D.; Liu, Y.; Yu, X.; Bai, X.; Li, H.; Chen, L. Enabling Stable Cycling of 4.2 V High Voltage All-Solid-State Batteries with PEO-Based Solid Electrolyte. Adv. Funct. Mater. 2020, 30 (22), 1909392.

(6) Yang, X.; Jiang, M.; Gao, X.; Bao, D.; Sun, Q.; Holmes, N.; Duan, H.; Mukherjee, S.; Adair, K.; Zhao, C.; Liang, J.; Li, W.; Li, J.; Liu, Y.; Huang, H.; Zhang, L.; Lu, S.; Lu, Q.; Li, R.; Singh, C. V.; Sun, X. Determining the limiting factor of the electrochemical stability window for PEO-based solid polymer electrolytes: main chain or terminal-OH group? Energy \& Environ. Sci. 2020, 13 (5), 1318-1325. 